\title{
Autonomic Nervous Cardiovascular Regulation in Borderline Hypertension
}

STEVO JULIUS, MD, FACC

MURRAY ESLER, MBBS, PhD

Ann Arbor, Michigan
From The Hypertension Section, Department of Internal Medicine, University of Michigan Medical Center, Ann Arbor, Mich.

Address for reprints: Stevo Julius, $M D, R$ 6669 Kresge Medical Research Building, University of Michigan Medical Center, Ann Arbor, Mich. 48104.
Borderline hypertension attracts investigative interest since it is an early predictor of established hypertension and its sequelae. This condition offers the opportunity of studying arterial hypertension at its inception, before the development of secondary pressure-related changes. A number of abnormalities of the circulation have been described in borderline hypertension. The peripheral resistance is either elevated or inappropriately adjusted to the prevailing increased cardiac output and blood flow. Cardiac output, heart rate and stroke volume are elevated in a proportion of patients. Decreased plasma volume, enhanced pressor responsiveness and elevated plasma renin activity have also been noted. All these changes could hypothetlcally be explained by a neurogenic mechanism. Although the experimental evidence supporting a neurogenic origin of borderline hypertension is incomplete and often indirect, most findings point toward an abnormal autonomic control of the circulation in this disorder.

It is postulated that in a subgroup of patients with borderline hypertension a neurogenic mechanism is in fact operative. There is a need for further characterization of this category of borderline hypertension and for description of its natural history, particularly in relation to the possible subsequent development of essential hypertension.

Borderline hypertension could be best described as a condition of elevated blood pressure with readings not sufficiently high to warrant early treatment. A uniformly accepted definition of borderline hypertension is not available. For the purposes of this review, we will report results obtained in subjects who (1) had blood pressure intermittently above $150 / 90 \mathrm{~mm} \mathrm{Hg}$, with some readings in the normal range, or (2) had minimal persistent pressure elevations, with average readings above $150 / 90$ but below $160 / 100 \mathrm{~mm} \mathrm{Hg}$.

Borderline hypertension attracts investigative interest since it appears to be an early nredictor of future established hypertension (Fig. 1). ${ }^{1}$ This is a finding that has been amply confirmed. ${ }^{2}$ Furthermore, borderline hypertension carries an excess of overall mortality (Fig. $2)^{1,3-5}$ and specific cardiovascular morbidity (Fig. 3)..$^{6-9}$

As arterial hypertension develops, many secondary cardiovascular changes occur. Resetting of arterial baroreceptors, ${ }^{10,11}$ restructuring of resistance vessels ${ }^{12,13}$ and alteration in cardiac performance ${ }^{14,15}$ are examples. Therefore, observations on the pathophysiology of established hypertension need to be subjected to close scrutiny to determine whether they are related to the initiation of the pressure elevation or are a secondary consequence of the high blood pressure.

This problem is obviated in borderline hypertension. The advantage of studying very mild hypertension before the development of secondary pressure-related changes is self-evident, but limitations must also be appreciated. Whereas in borderline hypertension the 


\section{LATER OCCURRENCE OF SUSTAINED HYPERTENSION, BY AGE, IN THOSE WITH AND WITHOUT TRANSIENT HYPERTENSION}

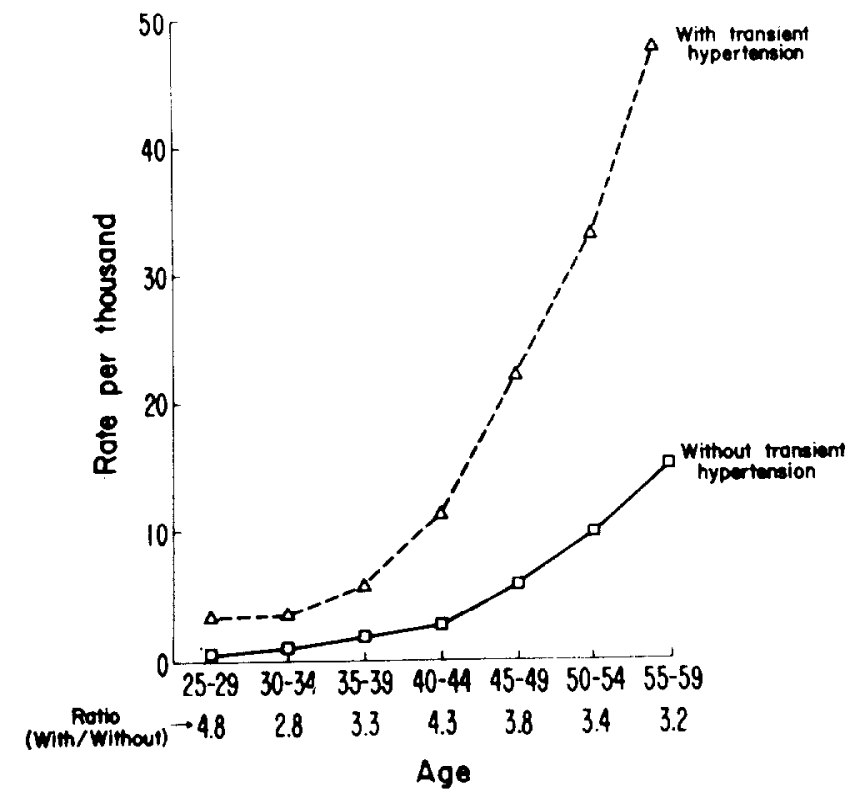

FIGURE 1. Prevalence of future sustained hypertension in normotensive subjects and patients who initially had transient (borderline) hypertension. Each cohort was followed for 5 years. Adapted from Levy et al. ${ }^{1}$ (Courtesy of The Journal of the American Medical Association.)

risk for future hypertension is higher than in the general population, not all patients will later have sustained hypertension. While assessing the significance of the abnormalities in autonomic nervous system function in borderline hypertension one must keep in mind, the advantages and limitations of borderline hypertension as a model of sustained hypertension.

\section{Neurogenic Borderline Hypertension- Testing a Hypothesis}

Figure 4 presents a list of aberrations observed in borderline hypertension. ${ }^{16-53}$ The figure also illus

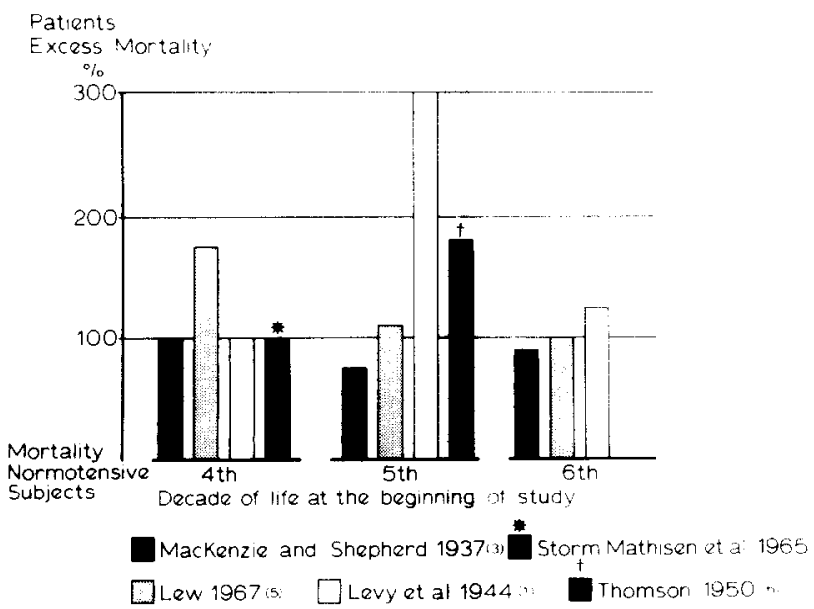

FIGURE 2. Mortality in patients with borderline hypertension compared with that in the general population or matched controls. In all reviewed papers the patients showed significant excess mortality. trates the hypothesis that most of the observed aberrations in borderline hypertension can be explained by a neurogenic mechanism. Whereas one can draw logical and conceptual support for this hypothesis, Figure 4 also illustrates that, in our assessment, supportive facts are neither always available nor invariably strong. A detailed review of the evidence for and against the role of the nervous system in borderline hypertension follows.

\section{Biochemical indexes of Overall Sympathetic Nervous System Activity}

Attempts have been made to utilize the biochemical events accompanying sympathetic nervous discharge to quantitate overall sympathetic nervous activity in man. This has been done by measuring the concentration in plasma or excretion in urine of norepinephrine, dopamine-beta-hydroxylase and cyclic adenosine monophosphate. Findings in borderline hypertension will be presented.

Catecholamines: Plasma epinephrine has its oriyins in the secretions of the adrenal medulla. Norepinephrine is the neurotransmitter of the sympathetic nerves, but is released also from the adrenal medulla. However, the sympathetic nerves, particularly of the heart. ${ }^{54}$ are thought to be the major source of plasma norepinephrine.

Norepinephrine released from sympathetic nerve terminals produces postsynaptic excitation, and is "inactivated" by several different methods, including active reuptake into the nerve terminal, diffusion into the blood, and to some extent local enzymatic destruction by catechol-o-methyltransferase. ${ }^{55}$ Plasma levels of norepinephrine are determined by the amount of transmitter released, the activity of the local mechanisms of neuronal reuptake and enzymatic degradation, the rate of diffusion into the circulation. and the rate of extraction of norepinephrine from plasma. Despite the multiplicity of factors potentially influencing norepinephrine levels, there is good cvidence that the plasma norepinephrine con-

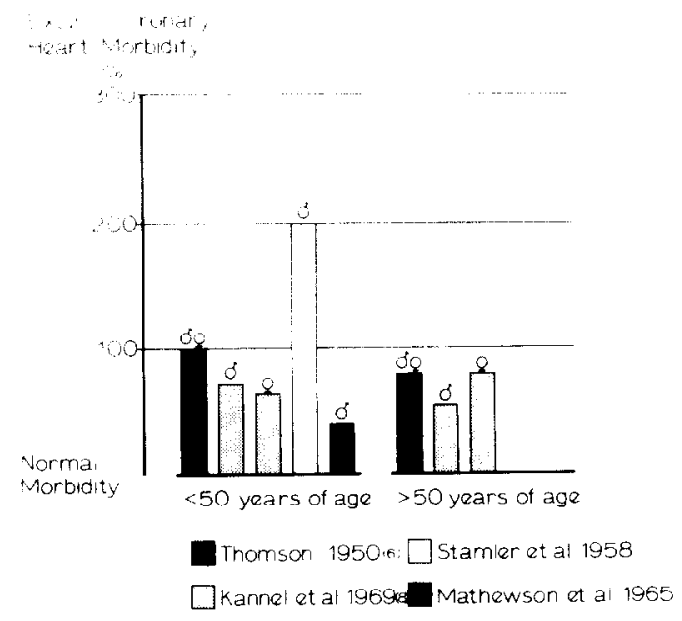

FIGURE 3. Coronary vascular morbidity in subjects with borderline hypertension compared with normotensive controls. An excess morbidity was observed in all studies. 
centration is at least a qualitatively valid, if somewhat quantitatively inexact, index of sympathetic nervous activity. ${ }^{56}$

To what extent the urinary excretion of catecholamines in man reflects plasma catecholamine concentrations remains something of an open question. Although the assumption is often made that epinephrine and norepinephrine excretion in urine is a function only of plasma concentration and glomerular filtration rate, ${ }^{57,58}$ active renal tubular transport mechanisms for catecholamines are possible. ${ }^{59,60}$ However, if plasma norepinephrine concentration is estimated by a reverse clearance technique, based on urinary norepinephrine excretion rate and glomerular filtration rate ${ }^{57,58}$ a figure is obtained that agrees very closely with the value determined by direct double isotope derivative assay of norepinephrine in plasma. ${ }^{57}$

Catecholamine levels in plasma and urine have been studied extensively in established essential hypertension. There is now fairly general agreement that an elevated norepinephrine concentration in plasma and an increased norepinephrine excretion in urine can be demonstrated in a proportion of patients with essential hypertension. ${ }^{18,57,61,62}$ In borderline hypertension the situation is less clear. Both Nestel and Doyle ${ }^{16}$ and Kuschke ${ }^{17}$ reported elevated urinary catecholamine excretion in patients with borderline hypertension. But this finding was not confirmed in a later study. ${ }^{57}$ DeQuattro and Chan ${ }^{18}$ noted an elevated plasma catecholamine concentration in only a minority of patients with borderline hypertension. Louis et al. ${ }^{62}$ noted a raised plasma norepinephrine concentration in patients with established essential hypertension, but not in a small number of those with borderline hypertension.

These conflicting findings in resting patients have prompted studies on the responsiveness to stimuli that activate the sympathetic nervous system. Excessive catecholamine responsiveness to mental stress ${ }^{19}$ and to postural stimulation ${ }^{20,58}$ has been reported in borderline hypertension. But interpretation of these findings of increased sympathetic responsiveness is difficult. The paradox is that noradrenergic responsiveness appears to be completely unrelated to the norepinephrine levels at rest in hypertension ${ }^{57}$; thus it is hard to infer that the stimulus functioned to expose an underlying, but difficult to demonstrate, state of sympathetic nervous overactivity.

It can be concluded that elevated plasma catecholamine concentrations and urinary catecholamine excretion probably exist in a proportion of patients with borderline hypertension, and that sympathetic overresponsiveness to some adrenergic stimuli probably occurs in a sizable minority. The significance of the blood pressure and catecholamine overresponsiveness is uncertain, but it has often been presumed that repeated pressor responses, in both human and animal prehypertension, ${ }^{63}$ may possibly lead to the subsequent development of permanent hypertension.

Dopamine-beta-hydroxylase: This enzyme, responsible for the conversion of dopamine to norepinephrine, is stored in vesicles in sympathetic nerve
FIGURE 4. Schematic presentation of the hypothesis that all observed abnormalities in borderline hypertension can be explained by a neurogenic mechanism. The "net" autonomic drive refers to the combined effects of the interplay of excitatory and inhibitory neurogenic impulses and the responsiveness of the target organ. References numbers for the basic observations are given in parentheses. The evidence for and against the hypothesis is discussed in the text.

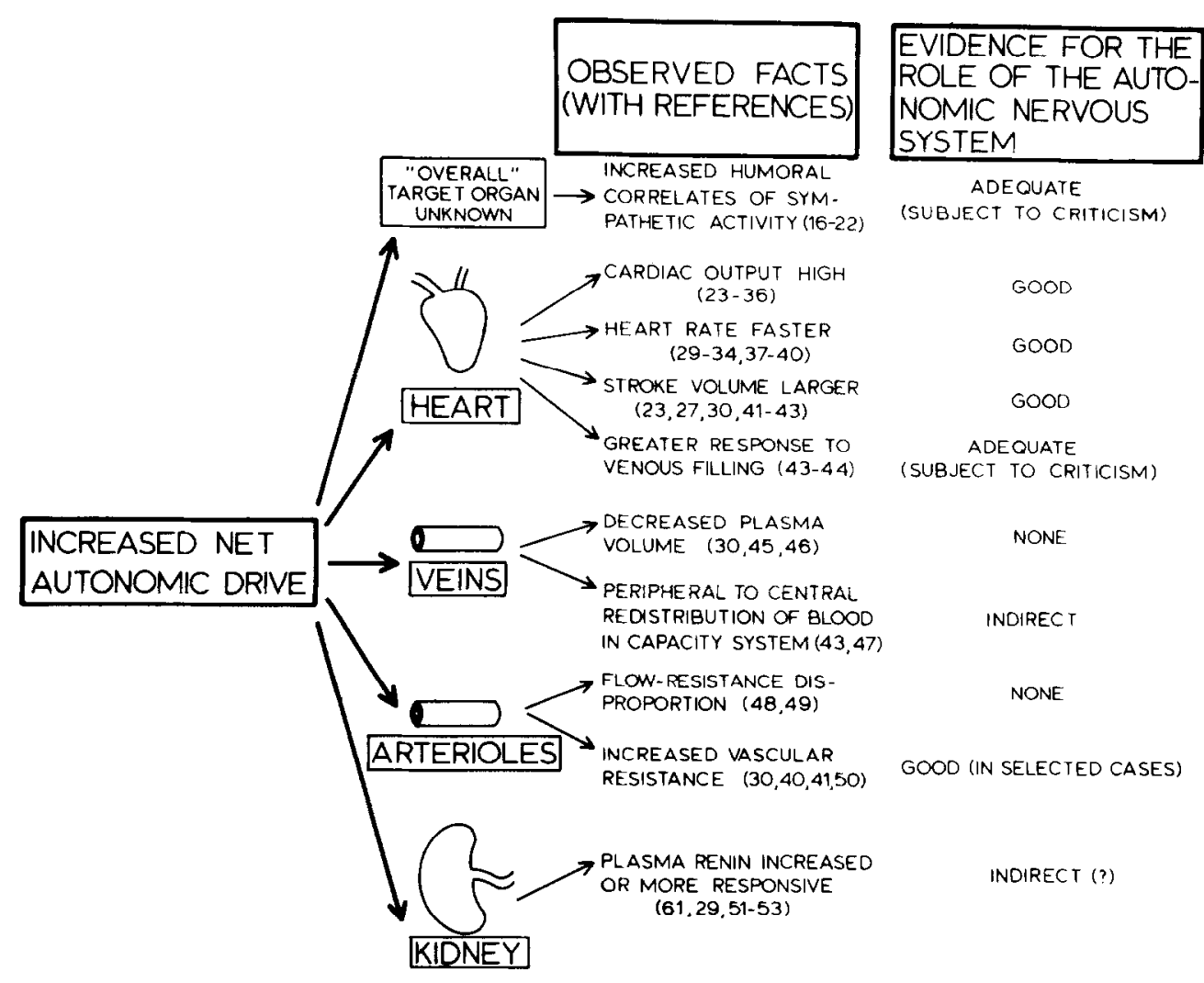


terminals. ${ }^{64}$ During sympathetic nerve discharge dopamine-beta-hydroxylase, together with norepinephrine, is subject to quantal release by a process of exocytosis. ${ }^{64}$ Since, unlike norepinephrine, dopamine-beta-hydroxylase is not subject to local reup take into the sympathetic nerve terminal after release, there were early hopes that its plasma concentration would provide a better index of sympathetic nervous system activity than plasma norepinephrine concentration. These hopes have not been fully realized. First, serum levels in normal subjects show a wide between-subject variation that seems to be determined largely by genetic factors ${ }^{65}$ unrelated to sympathetic nervous activity. Second, changes in serum dopamine-beta-hydroxylase with adrenergic stimuli such as dynamic exercise, isometric exercise and insulin-induced hypoglycemia have often been reported to be negligible, and proportionally much less than changes in plasma norepinephrine in re sponse to these stimuli. ${ }^{66-68}$

Notwithstanding these problems of interpretation, serum dopamine-beta-hydroxylase concentration has been the subject of scrutiny in patients with border. line and established hypertension. In established es sential hypertension, as in normal subjects, there is a wide scatter of individual serum values under conditions of rest, but mean concentrations have common ly, ${ }^{67,69}$ although not invariably, ${ }^{68}$ been reported as el evated. In borderline hypertension there is also a re-

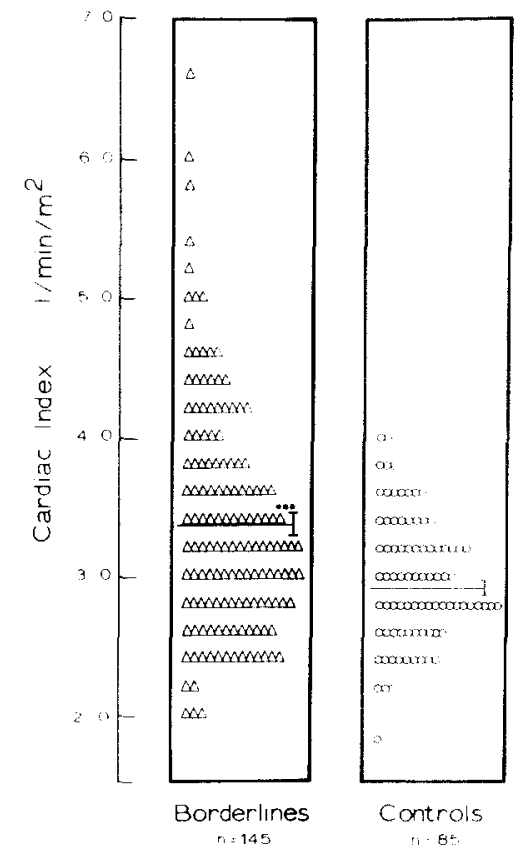

FIGURE 5. Our experience with levels of cardiac index in patients with borderline hypertension and normotensive control subjects. All measurements were taken by dye-dilution technique during recumbency 10 minutes after placement of the venous and arterial catheters. All subjects were men aged 18 to 35 years. Vertical bars represent standard errors of the mean. The mean value for patients was significantly higher $(P<0.001)$ but there was considerable overlap. About 30 percent of the patients in the study had values 2 standard deviations above the mean for normal subjects. (Reprinted courtesy of the American Heart Association, Inc. ${ }^{50}$ ) port of above-normal serum dopamine-beta-hydroxylase concentrations, ${ }^{21}$ but this has not been a universal finding. ${ }^{68,69}$ The basis for these discrepancies is not entirely clear, but they may possibly arise from the use of different techniques for determining the serum concentrations. Inactive precursors or metabolites may perhaps be detected by immunoassay but not enzymatic assay systems. Until it is cstablished that serum dopamine-beta-hydroxylase concentration is in fact a reliable indicator of overall sympathetic nervous system activity, any abnormalities detected in borderline hypertension will remain of uncertain significance.

Cyclic adenosine monophosphate: Generation of cyclic adenosine monophosphate follows stimulation of beta adrenergic receptors associated with membrane-bound adenylate cyclase. ${ }^{70}$ Urinary excretion of cyclic adenosine monophosphate has been utilized as an index of overall beta receptor stimulation in horderline hypertension. ${ }^{22}$ A normal rate of urinary excretion of cyclic adenosine monophosphate at rest in borderline hypertension, with an excessive response to postural stimulation, has been reported. ${ }^{22}$ However, since cyclic adenosine monophosphate functions as an intracellular "second messenger," 70 and the degree to which plasma and urinary concentrations of cyclic adenosine monophosphate reflect intracellular levels is not known, the significance of these findings is not clear.

\section{Cardiac Output, Heart Rate, Stroke Volume}

In established hypertension, the cardiac output is normal and peripheral resistance is elevated. ${ }^{71}$ Conversely, in a substantial proportion of patients with borderline hypertension, cardiac output is elevated at rest (hyperkinetic borderline hypertension). Since the early reports by Widimsky et al. ${ }^{23}$ and Eich et al. ${ }^{26}$ this finding, which has been repeatedly confirmed, has aroused considerable investigative interest. The interest focuses on the concept of autoregulation," 72 which postulates that in hypertension there may exist a primary increase of cardiac output that later triggers an autorcgulatory increase of the peripheral resistance. This increased resistance acts to restrict cardiac output and finally a new balance is established, with a normal cardiac output and elevated peripheral resistance. Thus, established arterial hypertension, a vascular disease in its later phases, may be cardiogenic in its inception.

Although the autoregulation from a high output to a high resistance state has not been adequately documented in man, ${ }^{73,74}$ the pivotal role that the heart may play in hypertension enhances the investigative interest in the mechanism of the elevation in cardiac output. We have been active in assessing the role of the autonomic nervous system. ${ }^{75}$ It can be seen from Figure 5 that cardiac output is increased in a sizable proportion of patients with borderline hypertension, but not in all. Patients with a substantial increase in cardiac output were selected for study and the role of the autonomic nervous system in the generation of 
this increase was investigated. The autonomic control of the heart was removed by intravenous injections of propranolol $(0.2 \mathrm{mg} / \mathrm{kg}$ body weight $)$ and atropine $(0.04 \mathrm{mg} / \mathrm{kg})$ (Fig. 6). With autonomic cardiac blockade, cardiac output levels fell into the normal range. Apparently the increased cardiac output was sustained by a neurogenic mechanism.

The role of the autonomic nervous system in cardiac control can be better understood when heart rate and stroke volume are analyzed separately. The heart rate in patients was increased (Fig. 6). After autonomic influences on the heart were removed, heart rate became normal. Thus there is no evidence that the intrinsic pacemaker in "hyperkinetic" borderline hypertension is overactive; the increased heart rate resulted solely from neurogenic influences.

Stroke volume is also increased in patients with "hyperkinetic" borderline hypertension (Fig. 6). Such an increase in stroke volume could potentially be due to neurogenic or humoral influences on myocardial contractility, to enhanced "intrinsic" contractile properties of the myocardium in borderline hypertension or to volume loading of the left ventricle (increased venous filling of the heart).

The question of possible increased venous filling leading to a high stroke volume in patients with borderline hypertension was investigated. Cardiopulmonary ("central") blood volume was used as an index of cardiac filling. Central blood volume correlates strongly with stroke volume under a wide range of circumstances ${ }^{43,44,76-79}$; this relation between central blood volume and stroke volume is taken to validate central blood volume measurements as an index of left ventricular filling. The elevation of stroke volume in borderline hypertension was claimed by Safar et al. ${ }^{47}$ to stem from an increased central blood volume. However, Ellis and Julius ${ }^{43}$ have shown that at similar levels of central blood volume, patients with "hyperkinetic" borderline hypertension have significantly higher stroke volumes than control subjects. This has been confirmed by Tarazi et al., ${ }^{44}$ who found an increased ratio of the stroke volume to central blood volume in borderline hypertension. Apparently in borderline hypertension there is an enhanced stroke volume response to venous filling. This enhanced response is neurogenic. This can be seen from Figure 6; after autonomic blockade of the heart, normalization of stroke volume followed. Further, after autonomic blockade the relation of stroke volume and central blood volume in "hyperkinetic" borderline hypertension becomes normal (Fig. 7).

In summary, the elevation of the cardiac output in patients with borderline hypertension stems from neurogenic influences on the heart.

\section{Abnormalities of Total Peripheral Resistance}

Total peripheral vascular resistance is normal at rest in "hyperkinetic" borderline hypertension. . $^{28,31,32}$ However, it must be appreciated that under normal circumstances, when blood flow increases, there is an appropriate decrease in vascular resistance so that blood pressure remains unchanged. In "hyperkinetic" borderline hypertension the elevated blood pressure stems from an inappropriate adjustment of the peripheral resistance to the increased tissue perfusion accompanying the increased cardiac output. ${ }^{48}$ This underlying abnormality of the peripheral resistance can be further brought to light if stimuli are applied that normally lead to a decrease in vascular resistance. Thus during mild exercise ${ }^{31,48}$ and plasma vol-
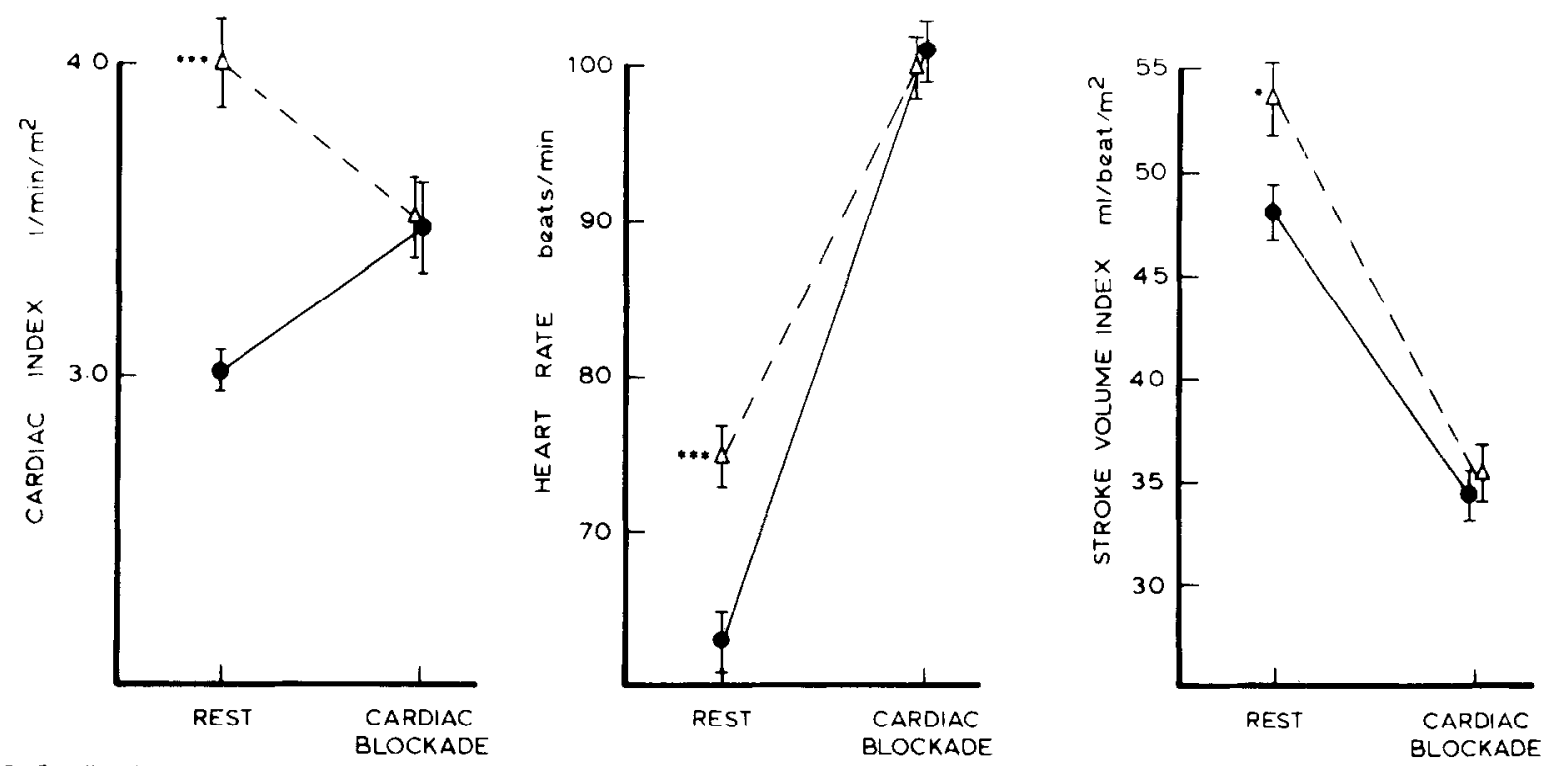

FIGURE 6. Cardiac index and its components at rest and after autonomic blockade with intravenous administration of propranolol and atropine in 25 young male patients with borderline hypertension (triangles) selected for their elevated cardiac output (more than 2 standard deviations above the mean of control subjects) and in 28 control subjects (circles). Significance of differences is denoted by asterisks ( $* * * P<0.001$, $*=P<0.05$ ). Bars represent standard errors of the mean. Note that after autonomic blockade the cardiac index and its components return to the normal range. (Reprinted from Clinical Science and Molecular Medicine, by permission. ${ }^{75}$ ) 


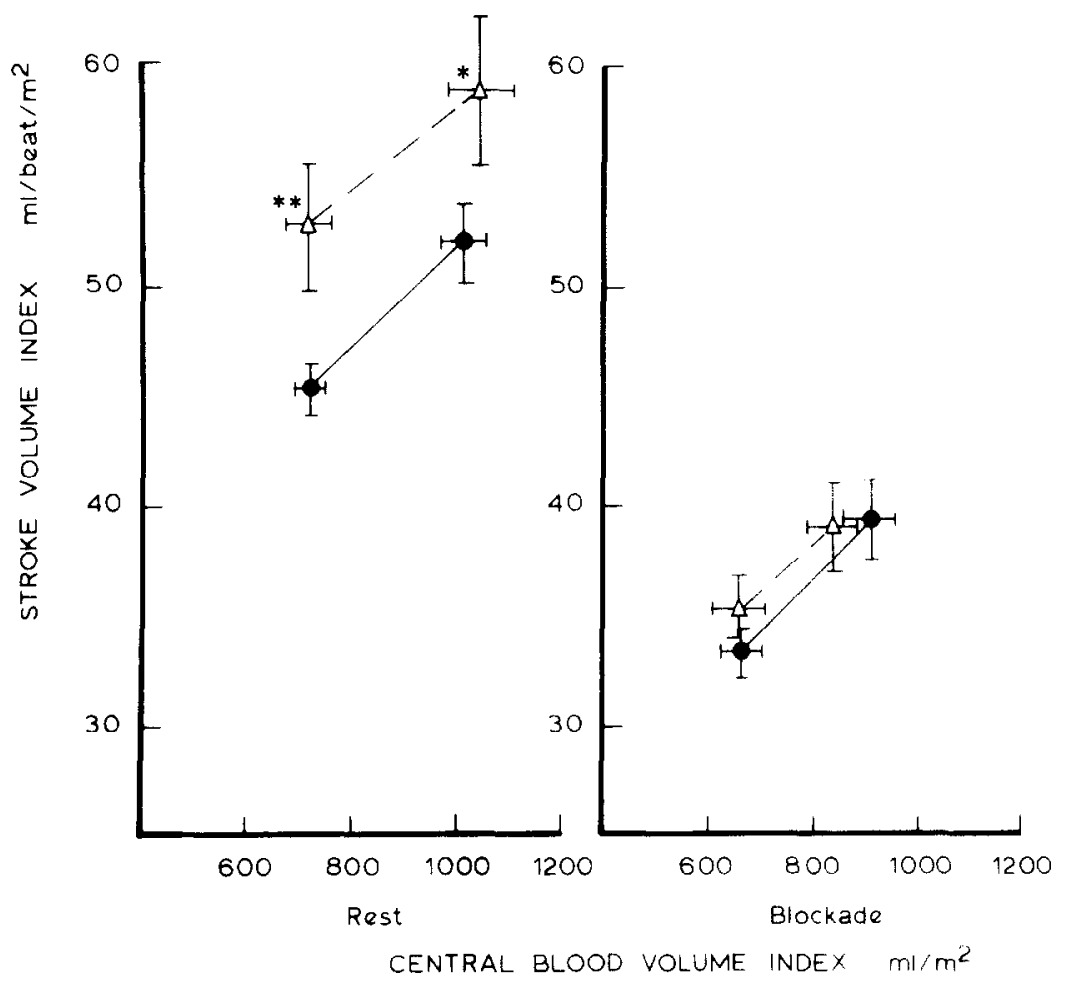

FIGURE 7. Relation between the stroke volume index and the central blood volume index in 17 young male patients with increased cardiac output and in 49 normal subjects. Symbols as in Figure 6. Mean central blood volume in normal subjects was used to form two groups ("low" and "high" central blood volume). Note that before cardiac autonomic blockade, central blood volume was similar in patients and normal subjects, but stroke volume was elevated in patients. After blockade, central blood volumes remained similar, but the previous elevation of stroke volumes in patients was abolished. (Reprinted from Clinical Science and Molecular Medicine, by permission. ${ }^{75}$ ) ume expansion, ${ }^{48}$ a subnormal decrease in peripheral resistance is observed in patients with borderline hy. pertension.

Whereas in "hyperkinetic" borderline hypertension experimental maneuvers must be employed to demonstrate the abnormality in vascular resistance, in subjects with borderline hypertension and a normal cardiac output, total peripheral resistance is in creased at rest. ${ }^{30,50}$ This increased resistance in borderline hypertension may well represent in part a structural impediment to flow, as suggested by Con way. ${ }^{80} \mathrm{He}$ found that under conditions of maximal vasodilation patients with even very mild hyperten sion failed to increase their forearm blood flow to the same degree as normotensive subjects.

The question of a possible neurogenic basis for the abnormality in vascular resistance in borderline hypertension was studied by us in a group of patients with normal cardiac output and increased peripheral resistance at rest. The change in total peripheral resistance produced by intravenous injection of the alpha adrenergic blocking drug phentolamine $(15$ $\mathbf{m g}$ ), after prior pharmacologic blockade of the heart, was investigated. ${ }^{52,81}$ As in normal subjects, in the majority of patients with borderline hypertension the peripheral resistance decreased very little. However, in approximately 30 percent of patients an immediate large reduction in peripheral resistance occurred, with normalization of the blood pressure. It appears that in a proportion of patients with borderline hypertension the elevated total peripheral vascular resistance is maintained by increased alpha adrenergic vasoconstrictor tone.

To summarize, in patients with "hyperkinetic" borderline hypertension total peripheral resistance is within normal limits, but inappropriately high for the level of cardiac output. In borderline hypertension with normal cardiac output, the increased peripheral resistance may in some cases be due to a structural (nonneurogenic) impediment to flow. However, in a proportion of patients there is evidence of enhanced alpha adrenergic vasomotor tone.

\section{Venous Function in Borderline Hypertension}

As discussed earlier in this review, central blood volume measurements reflect the dynamic relation between total blood volume, peripheral venous capacity and cardiopulmonary vascular distensibility. Ulrych et al. ${ }^{78}$ reported that patients with hypertension maintain a higher proportion of the total blood volume in the cardiopulmonary (central) capacity space than normal subjects. In a later work from the same laboratory, Tarazi et al. ${ }^{44}$ found a high central blood volume in renovascular hypertension but not in borderline and essential hypertension. Safar et al. ${ }^{47}$ found central blood volume to be elevated in borderline hypertension. This discrepancy among various studies may in part be a result of selection of patients. Thus in our laboratory, in "hyperkinetic" borderline hypertension ${ }^{43}$ the central blood volume was marginally elevated $(P<0.06)$, whereas in the overall population with borderline hypertension average values for central blood volume were normal. However, in subjects with borderline hypertension and low plasma renin activity central blood volume is distinctly elevated. ${ }^{82}$

In patients with a demonstrable increased central blood volume, the relation of peripheral vascular capacity to cardiopulmonary vascular compliance is distorted in the direction of reduced peripheral ve- 
nous distensibility. Such a restriction of peripheral venous capacity could stem from increased alpha adrenergic stimulation of veins. However, attempts to demonstrate increased alpha adrenergic venomotor tone in borderline hypertension have failed. In a small group of patients studied in our laboratory, in whom central blood volume at rest was elevated, administration of the alpha adrenergic blocking drug phentolamine (15 $\mathrm{mg}$ intravenously) failed to reduce central blood volume to normal limits. ${ }^{82}$ These preliminary results do not support a neurogenic basis for the elevated central blood volume but must be interpreted with caution. A rather large dose of phentolamine may be required to accomplish alpha adrenergic blockade of veins. ${ }^{83}$

Decreased plasma volume has been reported in borderline hypertension. The mechanism is unexplained but could be related to excess sympathetic activity. Thus it is known that stimuli, such as hypoxia, that greatly increase sympathetic nervous activity decrease plasma volume and increase venous tone. ${ }^{84}$ Apparently the increased sympathetic discharge causes postcapillary venoconstriction, leading to increased capillary filtration. Similarly, infusion of sympathomimetic amines causes a reduction in plasma volume by increasing postcapillary venous resistance, with consequent elevation of the capillary filtration index ${ }^{85}$ Conceivably such a sympathetically mediated increase in the capillary filtration index may be present in borderline hypertension. This hypothesis awaits experimental testing.

In summary, there is indirect evidence for increased venomotor tone in patients with borderline hypertension, but any possible relation between venous tone and increased sympathetic activity is yet to be clarified.

\section{Plasma Renin Activity}

Plasma renin activity at rest is elevated in some patients with borderline hypertension. ${ }^{14,20,29}$ In early studies ${ }^{14,20}$ dietary sodium intake was not assessed or controlled, so the finding was perhaps open to question. Subsequent investigations, performed under conditions of known sodium consumption, have confirmed the existence of high plasma renin activity in a proportion of patients with borderline hypertension. ${ }^{29,52}$ Mohlzan et al. ${ }^{29}$ found elevated plasma renin values at rest in patients with "hyperkinetic" borderline hypertension. Recently in our laboratory plasma renin activity was found to be elevated in 30 percent of patients with borderline hypertension. ${ }^{52}$ Stimulated renins may also be increased in borderline hypertension. Some patients show an excessive increase in plasma renin with head-up tilt or standing. ${ }^{20,51,53}$ The importance of renal sympathetic nerves in the control of renin release is well known. ${ }^{86}$ The question arises whether increased sympathetic tone and high plasma renin activity in borderline hypertension are associated phenomena.

One line of evidence explores the relation of sympathetic nervous and renin responsiveness to orthostatic stimulation. Kuchel et al. ${ }^{87}$ reported signifi-
TIME COURSE OF BP FALL WITH AUTONOMIC BLOCKADE IN HIGH RENIN BORDERLINE HYPERTENSION
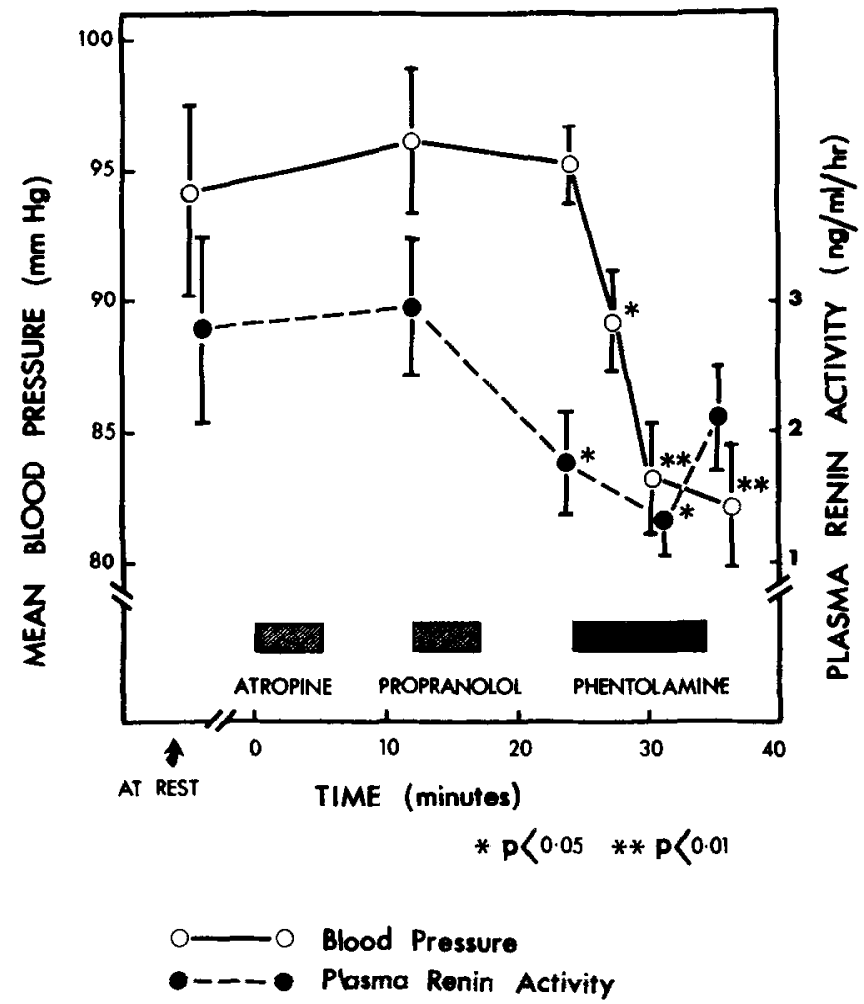

FIGURE 8. Sequential effect of atropine, propranolol and phentolamine on plasma renin activity and blood pressure in three patients with high-renin borderline hypertension. Note the substantial fall in plasma renin activity after propranolol without an appreciable effect on blood pressure. Blood pressure decreased abruptly after alpha adrenergic blockade with phentolamine with no further change in plasma renin activity. (Reprinted courtesy of P. Masson Publishers. $^{88}$ )

cantly greater orthostatic increases in plasma renin activity and urinary norepinephrine in subjects with borderline hypertension than in control subjects. Esler and Nestel ${ }^{20}$ observed a similar overresponsiveness to tilt. In addition, a positive correlation between changes in plasma renin and urinary norepinephrine was noted.

Another line of evidence bears on the relation of sympathetic tone at rest to renin status in borderline hypertension. We recently reported a finding of increased adrenergic vasomotor tone in high renin borderline hypertension. ${ }^{52}$ In response to alpha adrenergic blockade with intravenous phentolamine, patients with borderline hypertension and elevated plasma renin activity demonstrated an abnormally large reduction in total peripheral vascular resistance and blood pressure. That in such patients the sympathetic tone, and not the elevated renin level, is directly involved in the maintenance of the increase in blood pressure can be seen from Figure $8 .{ }^{88} \mathrm{After}$ an injection of propranolol plasma renin activity decreased substantially, but blood pressure remained unchanged. The administration of phentolamine then caused an immediate decrease in blood pressure without further reduction in plasma renin activity. 
Additional recent data indicate that the increased sympathetic drive involves the heart also; intravenously administered propranolol causes a greater reduction in heart rate in patients with high renin borderline hypertension than in normal subjects. ${ }^{89}$ Thus, the elevation of plasma renin activity appears to be only another facet of a widely distributed increase in sympathetic tone in borderline hypertension.

In summary, some patients with borderline hyper tension have elevated resting plasma renin activity. The renin responsiveness to orthostatic stimulation also is increased in a proportion of patients with borderline hypertension. There is evidence that the increased plasma renin activity in such patients is associated with nervous system overactivity.

\section{Mechanism of the Autonomic Nervous Abnormality}

In the previous section evidence was presented documenting abnormality of the autonomic nervous system in borderline hypertension. Possible mechanisms responsible for such changes in autonomic con trol of the circulation require elucidation.

\section{Abnormal Norepinephrine Dynamics at Sympathetic Nerve Endings}

Even with normal rates of sympathetic nervous discharge, disturbances of the mechanisms of norepinephrine inactivation after its release at the sympathetic nerve terminals could produce the manifestations of "sympathetic nervous system overactivity" catalogued in this review. Released norepinephrine is subject to active reuptake into the nerve terminals, diffusion into the circulation and local enzymatic destruction by catechol-o-methyltransferase. ${ }^{55}$ Any factor that impairs removal of norepinephrine from the synaptic cleft intensifies and prolongs the adrenergic response to nervous discharge.

In human hypertension, most attention has been directed to the possibility that neuronal reuptake of norepinephrine may be defective or that catechol-omethyltransferase activity may be diminished. Evidence of defective norepinephrine reuptake in essential hypertension has been reviewed by Mendlowitz et al ${ }^{90}$ The evidence is suggestive but indirect and not conclusive. The question of norepinephrine reuptake has not been studied specifically in borderline hypertension. Perhaps a guide to catechol-o-methyltransferase activity and norepinephrine methylation is the normetanephrine:norepinephrine excretion rate in urine. Brunjes ${ }^{91}$ found no evidence of diminished norepinephrine 0 -methylation in essential hypertension using this criterion. Catechol-o-methyltransferase activity has not been studied in borderline hypertension.

Sensitive methods for studying in man the dynamics of norepinephrine released at sympathetic varicosities are not available. The possibility that the observed manifestations of sympathetic overactivity in borderline hypertension are due to defective norepinephrine reuptake or subnormal catechol-o-methyltransferase activity remains open.

\section{Receptor Sensitivity and Vascular Reactivity}

The functional activity of an organ depends on the interaction between the excitatory and inhibitory autonomic impulses to which it is subjected, and the responsiveness of the organ. Consequently, apparent sympathetic overactivity observed in patients with borderline hypertension could stem from increased responsiveness to an essentially normal level of sympathetic nervous discharge.

The sensitivity of beta adrenergic receptors in horderline hypertension has been evaluated in several ways. Kuchel et al ${ }^{87}$ studied biochemical responses to prolonged infusion of a beta adrenergic agonist (isoproterenol) in borderline hypertension. The increases in plasma renin activity and urinary cyclic adenosine monophosphate excretion were greater than in normal subjects. The subjects with borderline hypertension were believed to show beta receptor hyperresponsiveness to isoproterenol, but it is not clear whether the larger changes in these patients in plasma renin activity or cyclic adenosine monophosphate signify (1) altered receptor sensitivity, or (2) differential effects of isoproterenol on blood flow distribution and metabolic clearance rates of renin and cyclic adenosine monophosphate.

A beta adrenergic receptor hypersensitivity is inferred in patients with "hyperdynamic beta adrenergic circulatory" state. ${ }^{92,93}$ The diagnostic hallmark of this condition is an excessive rise in the heart rate with short-term infusion of isoproterenol. Some, but not all, of these patients described by Frohlich et al. ${ }^{92}$ have borderline hypertension.

Cardiac beta adrenergic hypersensitivity is not present in the majority of patients with "hyperkinetic" borderline hypertension. Thus, Frohlich et al. ${ }^{14}$ did not find exaggerated heart rate and cardiac output responses to infusion of isoproterenol in $11 \mathrm{pa}$ tients with borderline hypertension who had normal resting heart rates but whose cardiac output was elevated. In our study, six patients with "hyperkinetic" borderline hypertension had resting tachycardia, but had a subnormal heart rate response to isoproterenol. ${ }^{50}$ In a recent paper, Ibrahim et al. ${ }^{94}$ described patients with established hypertension who maintained an elevated level of cardiac output. Only a small fraction of them exhibited increased cardiac responsiveness to isoproterenol.

The possible presence of vascular hyperreactivity in borderline hypertension must also be considered. Thus it has been reported that some patients with borderline hypertension show a greater response of blood pressure or vascular resistance to such stimuli as tilt, ${ }^{20,95}$ mental arithmetic ${ }^{19}$ and lower body negative pressure. ${ }^{96}$ All these responses are presumably mediated by the nervous system and were taken as an indicator of sympathetic overactivity in borderline hypertension. However, this assumption can be accepted only if patients' blood vessels respond to sympathetic stimulation in a normal fashion.

There is limited evidence of possible vascular hyperreactivity in borderline hypertension. Doyle and Fraser $^{97}$ studied forearm vascular responsiveness to 
intraarterial norepinephrine in normotensive offspring of hypertensive parents. Compared with sons of parents with normal blood pressure, the offspring of hypertensive parents exhibited increased vascular reactivity to norepinephrine. Suck et al. ${ }^{98}$ utilized digital plethysmography to assess vascular reactivity to norepinephrine in 18 patients with borderline hypertension. Increased vascular reactivity was found in 50 percent of those patients.

The question of vascular reactivity in borderline hypertension is not solved. Future research is needed to assess the prevalence of hyperreactivity in a large unselected population of patients with borderline hypertension, and to determine the relation between measures of vascular reactivity and indexes of sympathetic activity.

In summary, beta adrenergic hypersensitivity and vascular hyperreactivity have been described in patients with borderline hypertension. Beta adrenergic hypersensitivity appears to be infrequent. Vascular hyperreactivity perhaps exists and may possibly contribute to the pressor hyperresponsiveness recorded in borderline hypertension.

\section{Abnormal Integration of Autonomic Nervous Control}

We believe that in a majority of patients with borderline hypertension who show signs of abnormal autonomic regulation, the disorder originates in integrative areas of the medulla oblongata..$^{75}$ Figure 4 shows that biochemical indexes of sympathetic activ. ity are increased and that the increased net autonomic drive is distributed to various organ systems, and involves both alpha and beta adrenergic receptors. Such a generalized enhancement of sympathetic activity most likely originates in the central nervous system. In addition to sympathetic hyperactivity, changes in parasympathetic function have also been found in borderline hypertension. ${ }^{36}$ It can be seen in Figure 9 that in "hyperkinetic" borderline hypertension beta adrenergic blockade alone with intravenously administered propranolol was not sufficient to reduce cardiac output into the normal range. Only after parasympathetic blockade with atropine did the cardiac output become normal. Thus, both the sympathetic and parasympathetic control of the heart were involved in the elevation of cardiac output. After propranolol, cardiac output decreased more in patients than in control subjects, an indication of greater cardiac sympathetic drive in the subjects with borderline hypertension. Conversely, after administration of atropine, patients responded with a smaller increase in cardiac output, signifying a diminished degree of cardiac parasympathetic inhibition. Such a reciprocal relation, in which increased sympathetic discharge is coupled with a decreased parasympathetic inhibition, is characteristic of the functional organization in the higher integrative areas of autonomic control.

The cause of any existing functional changes in central nervous integrative areas in borderline hypertension is not readily evident, but a few possible mechanisms can be investigated. One such mecha-

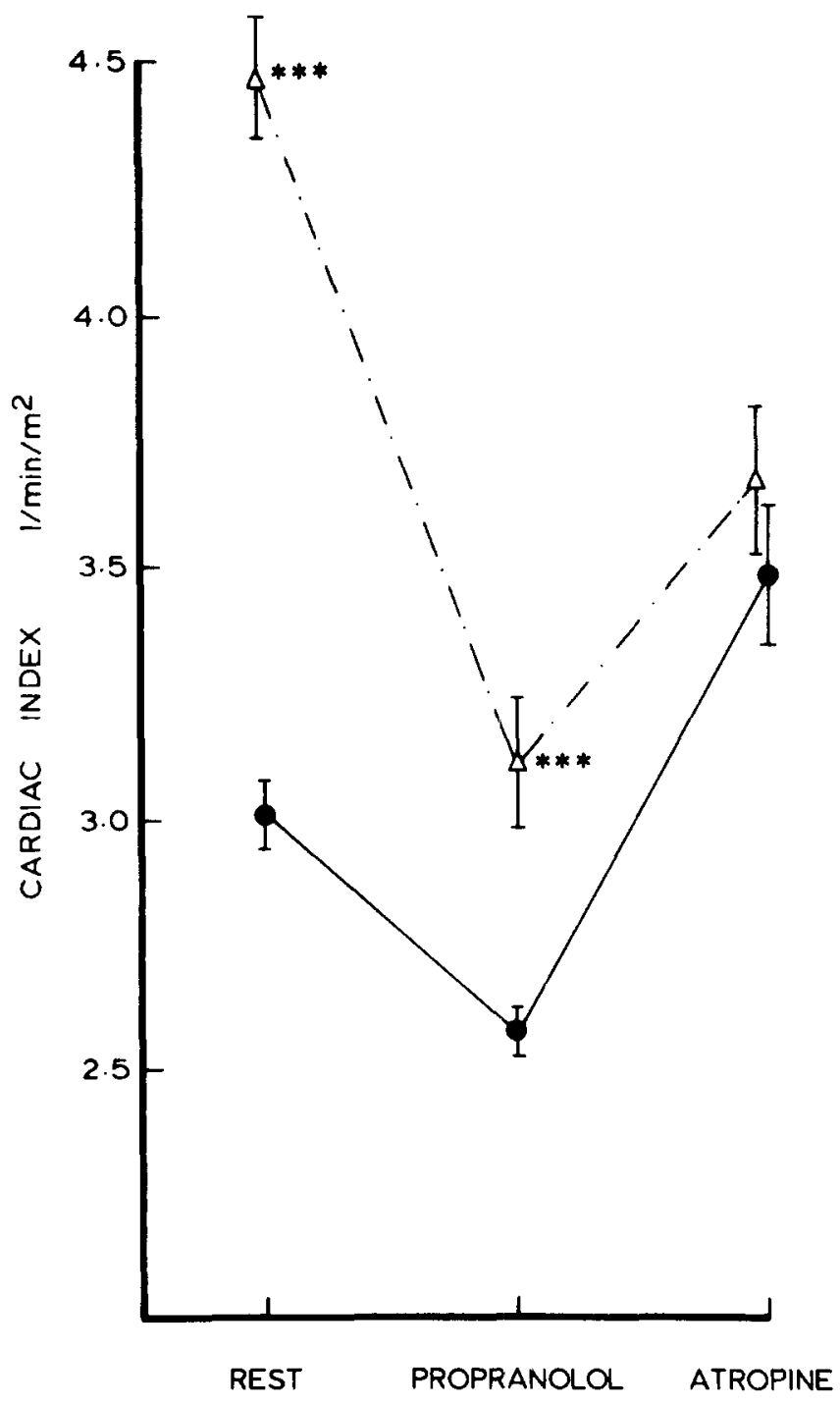

FIGURE 9. Cardiac index in 16 young male patients with "hyperkinetic" borderline hypertension and in 18 control subjects before and after stepwise autonomic blockade with propranolol $(0.2 \mathrm{mg} / \mathrm{kg}$ intravenously) and atropine $(0.04 \mathrm{mg} / \mathrm{kg}$ intravenously). Note that the cardiac output remained elevated after propranolol but became normal after atropine. Symbols as in Figure 6.

nism involves the functioning of the arterial baroreceptors; these are the source of one of the main modifying inputs converging on centers in the medulla oblongata. The baroreceptor control system could possibly be set by an unidentified peripheral or central mechanism to allow higher resting sympathetic tone and decreased vagal inhibition. However, the rate of baroreceptor discharge cannot be adequately tested in human beings although the sensitivity of the arterial baroreceptors to acute blood pressure changes can be determined. Gribbin et al. ${ }^{99}$ observed reduced baroreflex sensitivity in some patients with borderline hypertension. $\mathrm{We}^{75}$ were unable to reproduce this finding, but Takeshita et al. ${ }^{100}$ recently confirmed Gribbin's observation. Consequently, the evidence is in favor of a reduction in arterial baroreflex sensitivity in borderline hypertension. Birkenhager et al. ${ }^{101}$ described excessive blood pressure variability 
in "hyperkinetic" borderline hypertension. Such wide blood pressure fluctuations could be expected with decreased buffering from insensitive baroreceptors. ${ }^{102}$

In addition to the input from peripheral mechanoreceptors, numerous other pathways converge upon centers in the medulla. One of the best studied is the influence from "defense areas" in the paleocortex. Stimulation of the defense area causes a substantial depression of baroreceptor function and elicits considerable withdrawal of cardiac parasympathetic tone. ${ }^{103}$ The "defense reaction" is seen as a physiologic response to stressful psychologic stimuli. It is therefore conceivable that some of the observed aberrations of autonomic control of the circulation in borderline hypertension stem from psychosomatic influences. Although there is dispute on the point, ${ }^{2}$ several studies ${ }^{104-107}$ indicate that patients with borderline hypertension may exhibit personality and behav. ioral characteristics that would make them more prone to stress and more sensitive to it. Consequently, a possible psychosomatic basis for the altered in. tegration of autonomic control in borderline hypertension cannot be ruled out.

\section{Summary}

This review can best be summarized by again re ferring to Figure 4. All abnormalities in patients with borderline hypertension cited in the figure can conceptually be explained by a neurogenic mechanism. Thus the observed elevation of various biochemical correlates of sympathetic activity may well reflect a generally increased sympathetic drive in borderline hypertension. All observed cardiac phenomena could conceivably be of neurogenic origin. Reduced plasma volume could be a consequence of increased venomo- tor tone producing enhanced capillary filtration. Abnormalities in peripheral vascular resistance could be caused by excess alpha adrenergic stimulation of arterioles. Elevated plasma renin activity could reflect increased renal sympathetic tone.

Whereas one can easily develop a conceptual framework for a neurogenic hypothesis of the pathophysiology of borderline hypertension, the experimental support for the hypothesis leaves much to be desired. The elevation of cardiac output, stroke volume and heart rate is probably of neurogenic origin. Increased alpha adrenergic vascular tone is present, but only in a minority of patients. Observed increases of plasma renin activity and renin responsiveness in a proportion of patients are conceivably neurogenic, but the evidence is indirect. In selected cases, but not in the majority of patients, biochemical indexes are indicative of the existence of increased sympathetic nervous activity. Whether increased adrenergic venomotor tone is present in borderline hypertension remains largely unexplored.

Despite some deficiencies, the weight of the evidence points toward an abnormality of autonomic control in patients with borderline hypertension. However, a clear syndrome of neurogenic borderline hypertension has not yet been delineated. Future research must be oriented toward identifying patients in whom all abnormalities are neurogenic. It is likely that such a fully neurogenic mechanism will be demonstrated only in a minority of patients. The evaluation of the natural history of this subset of "neurogenic" borderline hypertension in relation to the subsequent development of established hypertension and to the later presence or absence of identifiable neurogenic abnormality will represent a highly interesting and potentially rewarding topic for study.

\section{Reterences}

1. Levy RL, Hillman CC, Stroud WD, et al: Transient hypertension: its significance in terms of later development of sustained hypertension and cardiovascular-renal diseases. JAMA 126 : $829-833,1944$

2. Jullus S, Schork MA: Borderline hypertension-a critical review. J Chronic Dis 23:723-754, 1971

3. Mackenzle LF, Shepherd P: The significance of past hypertension in applicants later presenting normal average blood pressures. Proc Assoc Life Insur Med Dir Am 24:157-178, 1937

4. Mathisen HS, Loken H, Brox D, et al: The prognosis in essential hypertension. Scand J Clin Lab Invest 17:Suppl 84:257 261, 1965

5. Lew EA: Blood pressure and mortality-life insurance experence. in, The Epidemiology of Hypertension: Proceedings of an International Symposium (Stamler J, Stamler R, Pullman TN, ed). New York, Grune \& Stratton, 1967, p 392-397

6. Thomson KJ: Some observations on the development and course of hypertensive vascular disease. Proc Med Sect Am Life Conv 38:85-112, 1950

7. Stamler J, Lindberg HA, Berkson DM, et al: Epidemiologica analysis of hypertension and hypertensive disease in the labor force of a Chicago utility company. Proc Council High Blood Pressure Res 7:23-52, 1958

8. Kannel WB, Schwartz MJ, McNamara PM: Blood pressure and risk of coronary heart disease: the Framingham study. Dis Chest 56:43-52, 1969
9. Mathewson FA, Brereton CC, Keltie WA, el al: The University of Manitoba follow-up study: a prospective investigation of cardiovascular disease-Il. Build, blood pressure and electrocardiographic factors possibly associated with the development of coronary heart disease. Can Med Assoc J 92:1002-1006. 1965

10. McCubbin JW, Green JH, Page IH: Baroreceptor function in chronic renal hypertension. Circ Res 4:205-210, 1956

11. Korner PI, West MJ, Shaw J, et al: "Steady state" properties of the baroreceptor-heart rate reflex in essential hypertension in man. Clin Exp Pharmacol Physiol 1:65-76, 1974

12. Folkow B, Grumby G, Thulesius $\mathbf{O}$ : Adaptive structural changes of the vascular wall in hypertension and their relationship to control of the peripheral resistance. Acta Physiol Scand 44:255-272, 1958

13. Sivertsson R: The hemodynamic importance of structural vascular changes in essential hypertension. Acta Physiol Scand 79:Suppl 343:3-56, 1970

14. Frohilich ED, Kozul VJ, Tarazi RC, et al: Physiological comparison of labile and essential hypertension. Circ Res 46:Suppl 1: $55-69,1970$

15. Frohlich ED, Tarazi RC, Dustan HP: Clinical-physiological cor * relation in the development of hypertensive heart disease. Circulation 44:446-455, 1971

16. Nestel PJ, Doyle AE: The excretion of free noradrenaline and adrenaline by healthy young subjects and by patients with essential hypertension. Aust Ann Med 17:295-299, 1968 
17. Kuschke HJ: Investigations about the state of excitation of the sympathetic nervous system and of the adrenal medulla in cardiovascular diseases. Arch Kreislaufforsch 36:104-148, 1961

18. DeQuattro V, Chan S: Raised plasma catecholamines in some patients with primary hypertension. Lanoet 1:806-809, 1972

19. Nestel PJ: Blood pressure and catecholamine excretion after mental stress in labile hypertension. Lancet 1:692-694, 1969

20. Esler MD, Nestel PJ: Renin and sympathetic nervous system responsiveness to adrenergic stimuli in essential hypertension. Am J Cardiol 32:643-649, 1973

21. Stone RA, Gunnells JC, Roblnson RR, et al: Dopamine- $\beta$-hydroxylase in primary and secondary hypertension. Circ Res 22:Suppl l:47-56, 1974

22. Hamet P, Kuchel O, Genest J: Effect of upright posture and isoproterenol infusion on cyclic adenosine monophosphate excretion in control subjects and patients with labile hypertension. J Clin Endocrinol Metab 36:218-226, 1973

23. Widlmsky J, Fejtarová MH, Fejfar Z: Changes of cardiac output in hypertensive disease. Cardiologia 31:381-389, 1957

24. Bello CT, Sevy RW, Harakal C, et al: Relationship between clinical severity of disease and hemodynamic patterns in essential hypertension. Am J Med Sci 253:194-208, 1967

25. Bello CT, Sevy RW, Harakal C: Varying hemodynamic patterns in essential hypertension. Am J Med Sci 250:24-35. 1965

26. Elch RH, Peters RJ, Cuddy RP, et al: The hemodynamics in labile hypertension. Am Heart J 63:188-195, 1962

27. Finklelman S, Worcel M, Agrest A: Hemodynamic patterns in essential hypertension. Circulation 31:356-368, 1965

28. Jullus S, Conway J: Hemodynamic studies in patients with borderline blood pressure elevation. Circulation 38:282-288, 1968

29. Molzahn M, Dlssmann T, Hallm S, of al: Orthostatic changes of haemodynamics, renal function, plasma catecholamines and plasma renin concentration in normal and hypertensive man. Clin Sci 42:209-222, 1972

30. Safar ME, Weiss YA, Levenson JA, et al: Hemodynamic study of 85 patients with borderline hypertension. Am J Cardiol 31: 315-319, 1973

31. Lund-Johansen P: Hemodynamics in early essential hypertension. Acta Med Scand Suppl 482:1-105, 1967

32. Sannerstedt R: Hemodynamic response to exercise in patients with arterial hypertension. Acta Med Scand Suppl 458:1-83, 1966

33. Sannerstedt R: Hemodynamic findings at rest and during exercise in mild arterial hypertension. Am J Med Sci 258:70-79, 1969

34. Sannerstedt R, Jullus S, Conway J: Hemodynamic responses to tilt and beta-adrenergic blockade in young patients with borderline hypertension. Circulation 42:1057-1064, 1970

35. Juchems von R, Wertz U: Central hemodynamics of the hyperkinetic syndrome under blockade with beta receptors. Munch Med Wochenschr 111:2567-2571, 1969

36. Jullus S, Pascual AV, London R: Role of parasympathetic inhibition in the hyperkinetic type of borderline hypertension. Circulation 44:413-418, 1971

37. Dissmann T, Gotzen R, Molzahn $M$, et al: Blood circulation mechanics in essential and renovascular hypertension. Arch Kreislaufforsch 63:226-256, 1970

38. Jullus S, Ellls CN, Pascual AV, et al: Home blood pressure determination. Value in borderline ("labile") hypertension. JAMA 229:663-666, 1974

39. Frohlich ED, Ulrych M, Tarazl RC, et al: A hemodynamic comparison of essential and renovascular hypertension. Circulation 35:289-297, 1967

40. Kramer AA, Shkhvatsabaya LV, Eventov AZ, et al: Peculiarities of the central and renal hemodynamics in patients with hypertensive disease at its early stage. Kardiologila 12:31-40, 1972

41. Werkö L, Lagerlöf $H$ : Studies on the circulation in man (IV). Cardiac output and blood pressure in the right auricle, right ventricle and pulmonary artery in patients with hypertensive cardiovascular disease. Acta Med Scand 133:427-436, 1949

42. Kuramoto K, Murata K, YazakI Y, ot al: Hemodynamics in the juvenile hypertension with special reference to the response to propranolol. Jap Circ J 32:981-987, 1968
43. Ellis CN, Jullus S: Role of central blood volume in hyperkinetic borderline hypertension. Br Heart J 35:450-455, 1973

44. Tarazl RC, Ibrahim MM, Dustan HP, ot al: Cardiac factors in hypertension. Circ Res 34, 35:Suppl I:I-213-I-243, 1974

45. Jullus S, Pascual AV, Relly K, ot al: Abnormalities of plasma volume in borderline hypertension. Arch Intern Med 127:116119,1971

46. Dissman TH, Gotzen R, Muller B, ot al: Plasma and red blood cell volume in incipient essential hypertension. Verh Dtsch Ges Inn Mod 73:604-607, 1967

47. Safar ME, Wolss YA, London GM, et al: Cardiopulmonary blood volume in borderline hypertension. Clin Sci Mol Med 47: 153-164, 1974

48. Jullus S, Pascual AV, Sannerstedt R, et al: Relationship between cardiac output and peripheral resistance in borderline hypertension. Circulation 43:382-390, 1971

49. Feffar Z, Widlmsky J: Juvenile hypertension. In, Proceedings of the Joint W.H.O.-Czechoslovak Cardlology Soclety Symposium on the Pathogenesis of Essential Hypertension (Cort JH, Fencl V, Hejl Z, ed). Prague, State Medical Publishing House, 1961, p 33-42

50. Jullus S, Randall OS, Esler MD, et al: Altered cardiac responsiveness and regulation in the normal cardiac output type of borderline hypertension. Circ Res 36, 37:Suppl I:I-199-1-207, 1975

51. Molzahn M, Dissmann TH, Gotzen R, at al: The effects of acute and chronic diminution of cardiac output on blood pressure in early hypertension. Hemodynamic alterations after $\beta$ receptor blockade. Klin Wochenschr 49:476-484, 1971

52. Esler MD, Jullus S, Randall OS, ef al: Relation of renin status to neurogenic vascular resistance in borderline hypertension. Am J Cardiol 36:708-715, 1975

53. Werning C, Fischer N, Kapl E, ef al: Increased renin stimulation after orthostasis in lablle or borderline hypertension. Dtsch Med Wochenschr 97:1038-1039, 1972

54. DeQuattro V, Sjoerdsma A: Catecholamine turnover in normotensive and hypotensive man: effects of antiadrenergic drugs. $\mathrm{J}$ Clin Invest 47:2359-2373, 1968

55. Wurtman R: Catecholamines. N Engl J Med 273:746-753, 1965

56. Yamaguchi N, deChamplain J, Nadeau R: Correlation between the response of the heart to sympathetic stimulation and the release of endogenous catecholamines into the coronary sinus of the dog. Circ Res 36:662-668, 1975

57. Esler MD, Nestel PJ: High catecholamine essential hypertension: clinical and physiological characteristics. Aust NZ J Med 3:117-123, 1973

58. Esler MD, Nestel PJ: Sympathetic responsiveness to head-up tilt in essential hypertension. Clin Sci 44:213-226, 1973

59. Rennick BR, Pryor MZ: Effects of autonomic drugs on renal tubular transport of catecholamines in the chicken. J Pharmacol Exp Ther 148:262-269, 1965

60. Overy HR, Pfister R, Chidsey CA: Studies on the renal excretion of norepinephrine. J Clin Invest 46:482-489, 1967

61. Engelman K, Portnoy B, Sjoerdsma A: Plasma catecholamine concentrations in patients with hypertension. Circ Res 27: Suppl I: 141-145, 1970

62. Louls WJ, Doyle AE, Anavekar S: Plasma norepinephrine levels in essential hypertension. N Engl J Med 288:599-601, 1973

63. Hallback M, Folkow B: Cardiovascular responses to acute mental "stress" in spontaneously hypertensive rats. Acta Physiol Scand 90:684-698, 1974

64. Viveros $\mathrm{OH}$, Argueros L, Kirshner N: Release of catecholamines and dopamine- $\beta$-oxidase from the adrenal medulla. Life Sci 7:609-618, 1968

65. Weinshilboum RM, Raymond FA, Elveback LR: Serum dopamine- $\beta$-hydroxylase activity: sibling-sibling correlation. Science 181:943-945, 1973

66. Oglhara T, Nugent CA: Serum DBH in three forms of acute stress. Life Sci 15:923-930, 1974

67. Wetterberg L, Aberg H, Ross SB, et al: Plasma dopamine- $\beta$ hydroxylase activity in hypertension and various neuropsychiatric disorders. Scand J Clin Lab Invest 30:283-289, 1972

68. Horwitz D, Alexander RW, Lovenberg W, et al: Human serum dopamine- $\beta$-hydroxylase. Relationship to hypertension and 
sympathetic activity. Circ Res 32:594-599, 1973

69. Geffen LB, Rush RA, Louis WJ, et al: Plasma dopamine- $\beta$ hydroxylase and noradrenaline amounts in essential hypertension. Clin Sci 44:617-620, 1973

70. Sutherland EW, Robison GA, Butcher RW: Some aspects of the biological role of adenosine $3^{\prime}, 5^{\prime}$-monophosphate (cyclic AMP). Circulation 37:279-306, 1968

71. Frels ED: Hemodynamics of hypertension. Physiol Rev 40 $27-54,1960$

72. Guyton AC, Coleman TG: Quantitative analysis of the pathophysiology of hypertension. Circ Res 24, 25:Suppl l:|-1-1-19, 1969

73. Eich RH, Cuddy RP, Smulyan H, et al: Hemodynamics in labile hypertensions: a follow-up study. Circulation 34:299-307. 1966

74. Coleman TG, Bower JD, Langford HG, et al: Regulation of arterial pressure in the anephric state. Circulation 42:509-514, 1970

75. Jullus S, Esler MD, Randall OS: Role of the autonomic nervous system in mild human hypertension. Clin Sci Mol Med 48: 243S-252S, 1975

76. Levinson GE, Frank MJ, Hellems HK: The pulmonary vascular volume in man. Measurement from atrial dilution curves. Am Heart J 67:734-741, 1964

77. Levinson GE, Paciflco AD, Frank MJ: Studies of cardiopulmonary blood volume: measurement of total cardlopulmonary blood volume in normal human subjects at rest and during exercise. Circulation 33:347-356, 1966

78. Ulrych M, Frohlich ED, Tarazl RC: Cardiac output and distribution of the blood volume in central and peripheral circulation in hypertensive and normotensive man. Br Heart $J$ 31:570-574, 1969

79. Milnor WR, Jose AD, McGalf CJ: Pulmonary vascular volume, resistance and compliance in man. Circulation 22:130-137. 1960

80. Conway J: A vascular abnormality in hypertension. A study of the blood flow in the forearm. Circulation 27:520-529, 1963

81. Julius S, Esler Mo, Randall OS, ef al: Neurogenic maintenance of peripheral resistance in borderline hypertension Acta Physiol Lat Am, in press

82. Esler MD, Julius $\mathbf{S}$, Randall $\mathbf{O}$, tal: Renin and indices of neurogenic activity in borderline hypertension. In, The Nervous System in Arterial Hypertension (Julius S, Esler MD, ed) Springfield, Ill, Charles C Thomas, in press

83. Mellander S: Comparative studies on the adrenergic neurohumoral control of resistance and capacitance blood vessels in the cat. Acta Physiol Scand 50:Suppl 176:1-86, 1960

84. Weil JV, Batlock DJ, Grover RF, et al: Venoconstriction in man upon ascent to high altitude: studies on potential mechanisms. Fed Proc 28:1160-1169, 1969

85. Cohn JN: Relationship of plasma volume changes to resistance and capacitance vessel effects of sympathomimetic amines and angiotensin in man. Clin Sci 30:267-278, 1966

86. Vander AJ: Effect of catecholamines and the renal nerves on renin secretion in anesthetized dogs. Am J Physiol 209:659662,1965

87. Kuchel $\mathbf{O}$, Cuche JL, Hamet $\mathbf{P}$, et al: The relationship between adrenergic nervous system and renin in labile hyperkinetic hy- pertension. Ir, Hypertenslon-1972 (Genest J, Koiw E, ed). New York, Springer-Verlag, 1972, p 118-125

88. Esler $\mathbf{M}$, Jullus $\mathbf{S}$, Randall $\mathbf{O}$ : Relationship of volume factors, renin, and neurogenic vascular resistance in borderline hypertension. In, The Nature and Prevention of Hypertensive Vascular Disease (Rorive G, ed). Paris, P. Masson Publishers, in press

89. Jullus S, Esler M, Randall O: Neurogenic borderline hypertension (abstr). Circulation 50:Suppl III:III-107, 1974

90. Mendlowitz M, Wolf RL, Gltlow SE: Catecholamine metabolism in essential hypertension. Am Heart J 79:401-407, 1970

91. Brunjes S: Catechol amine metabolism in essential hypertension. N Engl J Med 271:120-124, 1964

92. Frohlich ED, Dustan EP, Page IH: Hyperdynamic beta-adrenergic circulatory state. Arch Intern Med 117:614-619, 1966

93. Frohlich ED, Tarazi RC, Dustan HP: Hyperdynamic beta-adrenergic circulatory state: increased beta-receptor responsiveness. Arch Intern Med 123:1-7, 1969

94. Ibrahim MM, Tarazl RC, Dustan HP, et al: Hyperkinetic heart in severe hypertension: a separate clinical entity. Am J Cardiol 35:667-674, 1975

95. Frohlich ED, Tarazi RC, Ulrych $\mathbf{M}$, et al: Tilt test for investigating a neural component in hypertension. Circulation 36:387393, 1967

96. Mark AL, Lawton WJ, Abboud FM, et al: Effects of high and low sodium intake on arterial pressure and forearm vascular resistance in borderline hypertension. Circ Res 36, 37:Suppl I: l-194-l-198, 1975

97. Doyle AE, Fraser JRE: Essential hypertension and inheritance of vascular reactivity. Lancet 2:509-511, 1961

98. Suck AF, Mendlowitz M, Wolf RL, et al: Identification of essential hypertension in patients with labile blood pressure. Chest 59:402-406, 1971

99. Gribbin B, Pickering TG, Sleight P, et al: Effect of age and high blood pressure on baroreflex sensitivity in man. Circ Res 29:424-430, 1971

100. Takeshita A, Tanaka S, Kuroiwa A, et al: Reduced baroreceptor sensitivity in borderline hypertension. Circulation 51:738742,1975

101. Birkenhager WH, Van Es LS, Houwing A, et al: Studies on the lability of hypertension in man. Clin Sci 35:445-456, 1968

102. Cowley AW Jr, Liard JF, Guyton AC: Role of the baroreceptor reflex in daily control of arterial blood pressure and other variables in dogs. Circ Res 32:564-576, 1973

103. Hilton SM: Inhibition of baroreceptor reflexes on hypothalamic stimulation. J Physiol (l ond) 165:56P-57P, 1963

104. Harris RE, Sokolow M, Carpenter LG, et al: Response to psychologic stress in persons who are potentially hypertensive. Circulation 7:874-879, 1953

105. Kalis BL, Harris RE, Bennett LF, et al: Personality and life history factors in persons who are potentially hypertensive. J Nerv Ment Dis 132:457-468, 1961

106. Harburg E, Jullus S, McGinn NF, et al: Personality traits and behavioral patterns associated with systolic blood pressure levels in college males. J Chronic Dis 17:405-414, 1964

107. Thomas CB: The psychological dimensions of hypertension. In Ref 5, p 332-339 